\title{
Pathogenesis and Treatment of Renal Osteodystrophy
}

\author{
Eduardo Slatopolsky $^{a}$ Esther Gonzalez ${ }^{b}$ Kevin Martin ${ }^{b}$ \\ aRenal Division, Washington University School of Medicine, St. Louis, Mo., and bDivision of Nephrology, \\ St. Louis University, St. Louis, Mo., USA
}

\section{Key Words}

Calcitriol · Hyperphosphatemia $\cdot$ Hypocalcemia . Parathyroid hormone $\cdot$ Chronic kidney disease

\begin{abstract}
Renal osteodystrophy is the term used to describe the many different patterns of the skeletal abnormalities that occur in patients with chronic kidney disease. The main two conditions are osteitis fibrosa, characterized by high bone turnover, increased osteoclastic and osteoblastic activity, and high levels of circulating parathyroid hormone (PTH) and adynamic bone disease characterized by low bone turnover and low levels of circulating PTH. Retention of phosphorus, decreased levels of calcitriol in blood, decreased levels of serum ionized calcium, reduced numbers of vitamin $D$ receptors and calcium sensors in the parathyroid gland, and skeletal resistance to the calcemic action of PTH play a major role in the development of renal osteodystrophy. This review will describe the current approach for the treatment of renal osteodystrophy.
\end{abstract}

Copyright $@ 2003$ S. Karger AG, Base

\section{Introduction}

Bone abnormalities have been known to be associated with chronic kidney disease for more than 60 years [1, 2]. Renal osteodystrophy is the term used to describe the many different patterns of the skeletal abnormalities that occur in patients with chronic kidney disease. Osteitis fibrosa is a manifestation of the effects of high levels of parathyroid hormone (PTH) on bone and is associated with a high bone turnover. Adynamic bone disease is characterized by an extremely low bone turnover, as is osteomalacia of aluminum accumulation. However, in the latter condition, there is an excess of osteoid tissue. In general, adynamic bone disease is associated with low levels of circulating PTH. These two forms of bone abnormalities may occur together, leading to a condition called mixed renal osteodystrophy. In addition, the skeleton can be involved by other processes such as amyloidosis due to the accumulation of $\beta_{2}$-microglobulin. Finally, the skeleton can also be influenced by other conditions such as osteoporosis, either postmenopausal or as a result of corticoid therapy.

\section{Secondary Hyperparathyroidism (SH)}

Hyperplasia of the parathyroid glands and elevation of the levels of PTH in blood have been demonstrated to occur early in the course of chronic kidney disease with

Eduardo Slatopolsky, MD

Renal Division, Washington University School of Medicine

660 South Euclid, Box 8126

St. Louis, MO 63110-1093 (USA)

Tel. +1 314362 7208, Fax +1 314362 7875, E-Mail eslatopo@im.wustl.edu
Fax + 41613061234

E-Mail karger@karger.ch www.karger.com
0253-5068/03/0215-0318\$19.50/0

Accessible online at: www.karger.com/bpu 
decreased renal function $[3,4]$. Several factors play a key role in the development of SH (fig. 1); among them, retention of phosphorus as the renal function is reduced, decreased levels of calcitriol in blood, decreased levels of serum ionized calcium, decreased levels of the vitamin D receptors and calcium sensor in the parathyroid gland, and a skeletal resistance to the calcemic action of PTH. Although all of these abnormalities independently play a key role in the development of $\mathrm{SH}$, it is important to emphasize that these factors are closely interrelated and that it is likely that one or more than one of these factors may predominate at different degrees of renal insufficiency and could considerably vary according to the particular type of kidney disease.

\section{Role of Phosphorus Retention}

Numerous studies have shown a major role of phosphate retention in the pathogenesis of $\mathrm{SH}$ and renal insufficiency [5-8]. Studies in experimental animals demonstrated that a reduction of phosphate in proportion to the decrease of the glomerular filtration rate was successful in preventing the development of hyperparathyroidism and its effects on bone in dogs with renal failure [9]. These observations were subsequently confirmed in studies performed in human subjects [10]. Although phosphate retention may decrease the levels of calcitriol and induce hypocalcemia with the secondary effects on parathyroid secretion, currently it is well known that phosphate per se independent of calcitriol and calcium has a direct effect on the parathyroid glands. Two groups of investigators [8, 11] successfully demonstrated, in in vitro studies, that the changes in extracellular phosphorus concentrations were associated with significant changes in PTH secretion under circumstances in which the concentrations of ionized calcium were unchanged. Investigators have reported that a high-phosphorus diet results in increased levels of PTH mRNA [12]. This effect appears to be posttranscriptional, and this observation led to investigations of an effect of phosphorus on regulating the stability of PTH mRNA [13]. A diet low in phosphorus also prevents an increase in parathyroid growth. The mechanism for the prevention of parathyroid growth by phosphorus restriction does not appear to involve the induction of apoptosis [14]. The mechanisms of the direct effect of phosphorus on parathyroid growth is not well understood at the present time, but it has been demonstrated that dietary phosphorus induces changes in the cell cycle regulator, $\mathrm{p} 21$, and that the expression of transforming growth factor alpha (TGF- $\alpha$ )

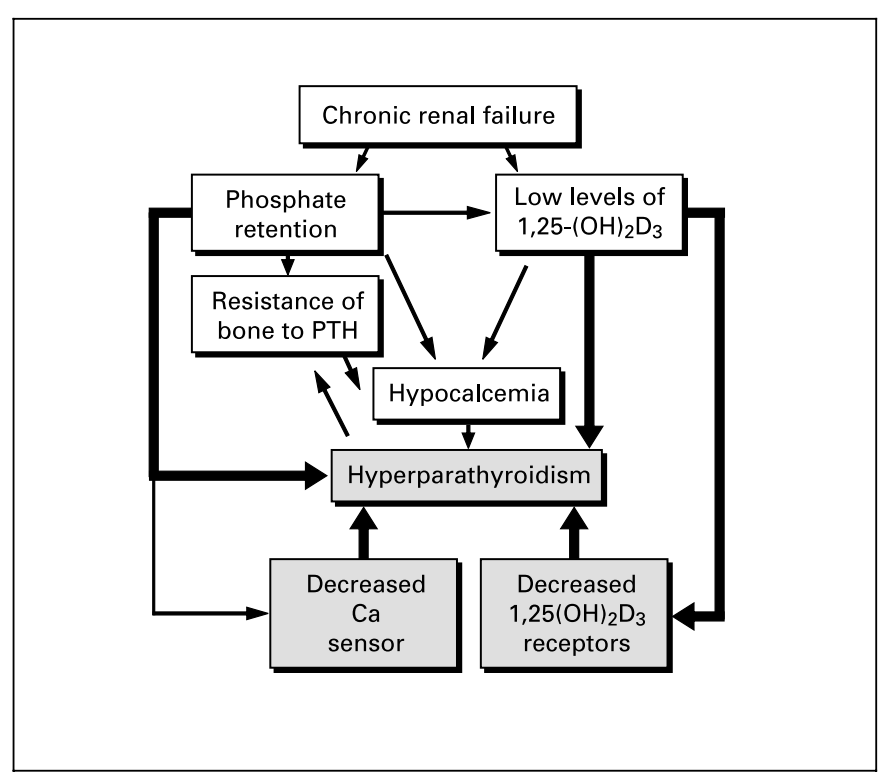

Fig. 1. Diagrammatic presentation of the factors involved in the pathogenesis of $\mathrm{SH}$.

appears to be involved. Thus, it has been demonstrated that in animals with renal failure a low-phosphate diet is associated with an increase in a cyclin-dependent inhibitor of the cell cycle, p21, at both mRNA and protein levels and that this is associated with prevention of parathyroid hyperplasia [15]. Further studies have suggested a role for TGF- $\alpha$ in that a high phosphorus concentration is associated with a marked increase in the expression of TGF- $\alpha$ after a few days of experimental renal failure. The increase in TGF- $\alpha$ in the parathyroid glands induced by a high-phosphorus diet and the increase of the proliferating cell nuclear antigen expression were specific for parathyroid tissue, since there was no change in intestinal or hepatic cell growth or TGF- $\alpha$ content. These changes in TGF- $\alpha$ are likely mediated through the epidermal growth factor receptor which upon activation will lead to activation of mitogen-activated protein kinase and the induction of cyclin- 1 to drive the cell from the $G_{1}$ to the $S$ phase [15].

\section{Role of Decreased Synthesis of Calcitriol}

A decreased production of calcitriol contributes to the development of SH. During the course of chronic renal failure, the levels of calcitriol in blood remain in the normal range until the glomerular filtration rate falls to below 
$50 \%$ of normal [16]. Since the PTH levels may already be elevated at this stage of chronic kidney disease, this normally will provide a stimulus to raise calcitriol levels to above the normal range. Thus, even normal levels of calcitriol may be inappropriately low in the presence of SH. Metabolic acidosis during the course of renal insufficiency could also decrease the levels of calcitriol and prevent the appropriate increase with higher levels of PTH. An additional mechanism which could limit the production of calcitriol during the course of chronic kidney disease could be decreased delivery of the precursor 25-hydroxyvitamin $\mathrm{D}$ bound to the circulating vitamin $\mathrm{D}$ protein (DBP) to the proximal tubule uptake mechanism. This has been described to involve megalin which is required for the uptake of 25-hydroxy-bound DBP into the cells, thus facilitating the delivery of the precursor to the 1hydroxylase [17]. A decrease in the number of vitamin D receptors in target tissue such as the parathyroid gland $[18,19]$ may also play an important role in the resistance of parathyroid hyperplasia to the administration of calcitriol. Investigators have shown that ultrafiltrates of uremic plasma appear to reduce the interaction of vitamin $D$ receptor with DNA in vitro [20]. It has, therefore, been postulated that uremic toxins may reduce the biological action of calcitriol in renal failure by interfering with the normal action of the vitamin $\mathrm{D}$ receptor.

\section{Role of Calcium}

Hypocalcemia is a potent stimulus for PTH secretion and parathyroid growth. Investigators have shown [21] that the adenylate cyclase activity in membranes prepared from hyperplastic parathyroid glands was less susceptible to inhibition by calcium than a membrane prepared from normal parathyroid tissue. This phenomenon was also demonstrated for calcium-regulated PTH secretion in vitro, in dispersed cells from parathyroid glands from patients with renal failure [22]. Several investigators have demonstrated alterations in the set point of calcium in hyperplasic tissue, i.e., that a higher calcium concentration is required to decrease PTH secretion by $50 \%$ in the abnormal tissue [23].

\section{Role of Calcitriol}

Calcitriol is a major regulator of the PTH secretion. Several investigators have demonstrated that calcitriol affects PTH secretion by an effect of the level of transcrip- tion on the PTH gene [24]. A decrease in the number of vitamin $\mathrm{D}$ receptors in the parathyroid glands of patients with chronic kidney disease may contribute to the pathogenesis of hyperparathyroidism by reducing the ability of calcitriol to inhibit the production of PTH. The administration of calcitriol leads to a dose-dependent increase in vitamin $\mathrm{D}$ receptor in the parathyroid glands in experimental animals [25]. Cozzolino et al. [26] demonstrated in uremic rats that administration of calcitriol or of the vitamin $\mathrm{D}$ analog 19-nor-1,25- $(\mathrm{OH})_{2} \mathrm{D}_{2}$ (paricalcitol; Zemplar $\left.^{\circledR}\right)$ was effective in controlling parathyroid hyperplasia [26]. In addition, the suppression of SH and parathyroid hyperplasia in these animals was associated with an enhanced expression of $\mathrm{p} 21$, the repressor of the cell cycle. In addition, the suppression of $\mathrm{SH}$ and parathyroid hyperplasia by calcitriol prevented the increase in parathyroid glands of TGF- $\alpha$ and epidermal growth factor receptor induced by high phosphate levels in uremic rats. In these studies, there was a significant correlation between the reduction of parathyroid gland growth and the reduction in TGF- $\alpha$ concentrations. It is important to emphasize that in experimental animals with established parathyroid hyperplasia, the administration of calcitriol induces a growth arrest of the parathyroid tissue, but the enlarged glands do not return to the normal size, and no apoptosis is observed.

\section{Role of Abnormal Parathyroid Growth}

Fukuda et al. [19] demonstrated that some parathyroid glands resected at parathyroidectomy have numerous nodules. Several studies demonstrated that the number vitamin D receptors was markedly decreased in these nodules. Subsequent investigations demonstrated that some of these nodules might undergo monoclonal expansions of parathyroid cells [27]. Thus the appearance of nodules in the parathyroid glands of hyperplastic parathyroid tissue indicates a more aggressive form and more resistance to the use of calcitriol.

\section{Histological Features of Renal Osteodystrophy}

Bone biopsy is the gold standard in the classification and diagnosis of renal osteodystrophy. The characteristic features of osteitis fibrosa and adynamic bone disease are listed in table 1 . The histological features of hyperparathyroidism and osteitis fibrosa are characterized by increased rate of bone formation, increased bone resorp- 
Table 1. Histological features of renal osteodystrophy [from ref. 57]

\section{Osteitis fibrosa}

Increased bone turnover

Increased number of osteoblasts

Increased osteoblast activity

Increased bone formation rate

Increased osteoid (often woven)

Increased number of osteoclasts

Increased osteoclast activity

Increased bone resorption

Endosteal fibrosis

Marrow fibrosis

Adynamic bone

Decreased bone turnover

Decreased number of osteoblasts

Decreased osteoblast activity

Decreased bone formaton rate

Normal or decreased osteoid

Decreased number of osteoclasts

Decreased osteoclast activity

tion, extensive osteoclastic and osteoblastic activity, and progressive increase in the endosteal peritrabecular fibrosis. A high osteoblastic activity is manifested by an increase in unmineralized bone matrix. The number of osteoclasts is also increased in osteitis fibrosa, as is the total resorption surface. In osteitis fibrosa, the alignment of strands of collagen in the bone matrix has an irregularly woven pattern that contrasts with the normal parallel alignment of strands of collagens in the lamellar bone. This disorganized collagen structure in woven bone may render the bone physically vulnerable in response to stress. Osteomalacia is characterized by an excess of unmineralized osteoid manifested as wide osteoid seams and marked by decreased mineralization rates. Until 15 years ago, in the United States aluminum accumulation played an important role in the development of osteomalacia. A special stain for the presence of aluminum can demonstrate that osteomalacic renal bone disease has large deposits of aluminum at the mineralization front, i.e., the interface between trabecular bone and osteoid. The decrease of osteomalacia correlates closely with the bone aluminum content. However, during the past 15 years, there has been a dramatic decrease in the ingestion of aluminum and in the presence of osteomalacia induced by aluminum accumulation. More recently, the development of adynamic bone disease has become a frequent appearance in patients maintained on dialysis. Adynamic bone disease is characterized histologically by features similar to those of osteomalacia, with a major difference being the absence of large osteoid seams. Biopsy specimens from such a patients appeared to have a markedly deficient cellular activity and a decreased number of both osteoclasts and osteoblasts. It appears that this is essentially a disorder of a decreased bone formation accompanied by a secondary decrease in bone mineralization.

Mixed uremic osteodystrophy has features of SH together with evidence of a mineralization defect. Thus, there is more osteoid than expected, and tetracycline labeling uncovers a concomitant mineralization defect.

\section{Treatment of Renal Osteodystrophy}

The objectives of treatment of osteodystrophy in patients with kidney failure are: (1) to maintain the blood levels of calcium and phosphorus as close to normal as possible; (2) to prevent the development of parathyroid hyperplasia or, if SH has already developed, to suppress the secretion of PTH; (3) to prevent extraskeletal deposition of calcium, and (4) to prevent or reverse the accumulation of substances such as aluminum and iron which can adversely affect the skeleton - general guidelines of the management of renal osteodystrophy are summarized in table 2 .

\section{Management of Phosphorus}

The control of phosphorus absorption during the course of chronic kidney disease is essential for the prevention of the above-described abnormalities. Recently, the new K/DOQI recommendations suggest $1.2 \mathrm{~g}$ protein/ $\mathrm{kg}$ for patients maintained on hemodialysis and $1.4 \mathrm{~g}$ protein $/ \mathrm{kg}$ for patients maintained on continuous ambulatory peritoneal dialysis. Such a protein intake makes it difficult to restrict the amount of phosphorus in the diet to $<1,200 \mathrm{mg} /$ day. Since approximately $60 \%$ of the phosphorus is absorbed, approximately $5,000 \mathrm{mg}$ of phosphorus per week enters the extracellular fluid. Most hemodialysis patients are dialyzed three times per week with roughly 800-900 mg phosphorus removed per treatment. Thus, most patients are in a positive phosphorus balance of approximately $300-500 \mathrm{mg} /$ day on the average. Consequently, more than $90 \%$ of the dialysis patients use phosphate binders to reduce the amount of phosphorus absorbed to achieve normal serum phosphorus levels of 3.5$4.5 \mathrm{mg} / \mathrm{dl}$ or $1.2-1.5 \mathrm{mmol} / \mathrm{l}$. Mucsi et al. [28] showed that 
Table 2. Guidelines for the management of renal osteodystrophy [from ref. 57]

Begin management early during the course of renal disease

Monitor PTH, if elevated, evaluate vitamin D status

Measure 25-(OH)-D levels

Supplement, if $25-(\mathrm{OH})-\mathrm{D}<30 \mathrm{ng} / \mathrm{ml}$

Ergocalciferol 50,000 U once a week $\times 4$, then once per month

If PTH is elevated, and the levels of 25-(OH)-D are normal, begin dietary phosphate restriction within limits of adequate protein intake

Phosphate binders with meals (maintain serum phosphorus at $3.5-5.5 \mathrm{mg} / \mathrm{dl}$ )

Calcium acetate

Calcium carbonate

Limit elemental calcium intake to $<2 \mathrm{~g} /$ day

Magnesium carbonate

If on dialysis, may need to decrease dialysate magnesium Sevelamer hydrochloride

Aluminum-based phosphate binders (monitor for toxicity)

Ensure adequate calcium intake

If on non-calcium-containing phosphate binder and/or using dialysate

If calcium $2.5 \mathrm{mEq} / \mathrm{l}$ give calcium supplement

Treat acidosis

Consider vitamin D sterols

In chronic renal failure, low-dose calcitriol or alfacalcidol

Monitor closely for toxicity

On dialysis, oral or intravenous vitamin D sterols with close monitoring for toxicity

Calcitriol

$1 \alpha-(\mathrm{OH}) \mathrm{D}_{3}$ or $1 \alpha-(\mathrm{OH}) \mathrm{D}_{2}$

Paricalcitol

Desired range for intact PTH 150-300 pg/ml; preliminary estimates for the range for PTH 1-84 assays are 50-60\% lower

Consider parathyroidectomy

For severe hyperparathyroidism with

Hypercalcemia

Persistent hyperphosphatemia

Failure to respond to therapy with vitamin D sterols and phosphate binders

Persistently elevated calcium phosphate production, leading to metastatic calcification

Transplant candidate with living-related donor

Calciphylaxis

patients on nocturnal hemodialysis (8-hour session six times/week) not only require no phosphate binders but that phosphorus must be added to the dialysate or that the ingestion of protein must be increased to prevent the development of hypophosphatemia. In the 60 s and $70 \mathrm{~s}$ the most commonly used phosphate binder contained aluminum. In the $80 \mathrm{~s}$ and $90 \mathrm{~s}$ aluminum was replaced by calcium salts. Aluminum causes neurological, skeletal, and hematological toxicity in end-stage renal disease patients, in some of whom calcium can lead to hypercalcemia as well as soft-tissue and cardiovascular calcification. In the past 10 years numerous publications have shown an increase in mitral and aortic valve calcification in endstage renal disease patients receiving calcium salts as phosphate binders $[29,30]$. A significant stiffness of the arterial wall has been demonstrated as complication in patients receiving large amounts of calcium salts [31]. In addition, Block et al. [32] demonstrated that a high $\mathrm{Ca}$ $\times \mathrm{P}$ product and a serum phosphorus concentration $>6.0 \mathrm{mg} / \mathrm{dl}$ are associated with an increased mortality. When the $\mathrm{Ca} \times \mathrm{P}$ product was $>70 \mathrm{mg}^{2} / \mathrm{dl}^{2}$, the mortality increased by $35 \%$. Thus, it is critical to control serum phosphorus within $3.5-5.5 \mathrm{mg} / \mathrm{dl}$ and try to maintain a Ca $\times$ P product $<55 \mathrm{mg}^{2} / \mathrm{dl}^{2}$. At the same time, it is important that the total amount of calcium patients ingest (dietary calcium plus phosphate binders containing calcium) is not $>2 \mathrm{~g} /$ day, since a high calcium intake has been associated with cardiovascular calcification. Recently, new phosphate binders have been developed. One of them, sevelamer $\left(\mathrm{RenaGel}^{\mathrm{R}}\right)$, is now widely used [33]. This phosphate binder is completely resistant to intestinal digestion and is not absorbed in the gastrointestinal tract. Studies have shown that this agent can effectively and safely lower serum phosphate without changing the serum calcium level. Long-term studies have shown a decrease in low-density lipoprotein cholesterol and in some patients also an increase in high-density lipoprotein cholesterol [34]. The mechanisms may be similar to those of cholesteramine by binding bile salts. Chertow et al. [35] in a multicenter study performed in the United States and in Europe compared the fate of sevelamer and calcium carbonate or calcium acetate in calcification affecting the cardiovascular system [35]. One group of patients received sevelamer and the other received calcium salts (calcium carbonate or calcium acetate) for a period of 52 weeks. The calcium contents of coronary artery and aorta were assessed by electron beam computed tomography. Both calcium salts and sevelamer controlled the $\mathrm{Ca} \times \mathrm{P}$ product, but patients receiving calcium salts became hypercalcemic more frequently (16 vs. $5 \%$ in the sevelamer group). More importantly, at the study completion, electron beam computed tomography demonstrated that the increase in the mean calcium score in coronary artery and aorta was greater in the subjects treated with calcium than in those treated with sevelamer. In addition, the C-reactive protein concentration decreased in the patients ingesting sevelamer and increased in the patients ingesting calcium salts. Since the cardiovascular mortality in dialy- 
sis patients is approximately $50-60 \%$, alterations in mineral metabolism are critical, as are inflammatory processes, hypertension, and alterations in lipid metabolism. The control of phosphorus is crucial, since an increased $\mathrm{Ca} \times \mathrm{P}$ product not only increases soft-tissue calcification, but phosphorus per se increases the expression of the transcriptional factor Cbfa-I. This factor has been shown to induce the differentiation of arterial smooth muscle cells into osteoblast-like cells that secrete osteocalcin, thus promoting vascular calcification [36].

Lanthanum carbonate is a trivalent cation at all $\mathrm{pH}$ values that binds phosphate to form lanthanum phosphate which is insoluble. Hutchison [37] demonstrated that the phosphate-binding capacity of lanthanum is similar to that of aluminum in vitro. Patients maintained on hemodialysis or continuous ambulatory peritoneal dialysis demonstrated that lanthanum carbonate can reduce serum phosphorus to approximately $5.0 \mathrm{mg} / \mathrm{dl}$. Further long-term studies are necessary in dialysis patents to determine the potential toxic effects of lanthanum accumulation, since a small amount of lanthanum is absorbed in the gastrointestinal tract.

\section{Dialysis Calcium Concentrations}

In the past, it was generally recommended that dialysate calcium concentrations be $3.0-3.5 \mathrm{mEq} / \mathrm{l}$. However, these values were obtained from patients who ingested aluminum containing phosphate-binding agents. More recently, studies have shown that using dialysate with a calcium concentration of $2.5 \mathrm{mEq} / \mathrm{l}$ is safe in patients taking calcium salts and vitamin $\mathrm{D}$ compounds.

\section{Use of Calcitriol}

Calcitriol is the most active metabolite of vitamin D and has been demonstrated to have a direct effect on parathyroid glands by suppressing synthesis and secretion of PTH as well by limiting parathyroid cell growth. The principal toxicities of calcitriol are due to its potent effect of increasing intestinal absorption of calcium and phosphorus as well as due to the potential to mobilize calcium and phosphate from bone. Hypercalcemia and/or hyperphosphatemia are common complications of such therapy that may limit its use at doses effective to suppress PTH. In the United States the intermittent intravenous administration of calcitriol is the common way to treat patients with hyperparathyroidism; however, investigators have administered oral calcitriol in an intermittent fashion (oral pulse) with good results [38, 39]. 1 $\alpha$-Hydroxyvitamin $\mathrm{D}_{3}$ or $\alpha$-calcitriol is widely used outside of the United States for the control of hyperparathyroidism. This vitamin D becomes hydroxylated in the 25 position by the hepatic 25-hydroxylase, resulting in the production of $1,25-(\mathrm{OH})_{2} \mathrm{D}_{3}$.

In an effort to utilize the action of vitamin $\mathrm{D}$ on the parathyroid gland and to minimize the toxicities of such therapy, structural alterations of the vitamin D molecule were undertaken to try to develop vitamin D analogs that may retain the effect on the parathyroid glands, but have a lesser effect on calcium and phosphate metabolism. These analogs would be relatively selected for parathyroid effects and would, therefore, be more useful therapeutic agents. Currently, there is experimental and clinical evidence for the efficacy of four of such vitamin D analogs which have been approved for the treatment of SH. Two of these analogs have been developed in Japan, 22-oxacalcitriol and falecalcitriol, and two have been developed in the United States, 19-nor-1,25-(OH $)_{2} \mathrm{D}_{2}$ and $1 \alpha$-hydroxy $\mathrm{D}_{2}$. 22-Oxacalcitriol differs from calcitriol by the substitution of an oxygen at the 22 position. This structure modification appears to reduce the affinity of 22-oxacalcitriol for the vitamin D receptor as well as for DBP. The decreased affinity for DBP results in rapid clearance from the circulation, and this may be a mechanism that accounts for low calcemic and phosphatemic effects of 22oxacalcitriol [40]. Falecalcitriol is an analog in which the hydrogens of carbons 26 and 27 have been substituted by fluorine atoms. This vitamin $\mathrm{D}$ analog has a greater activity than calcitriol and is considerably more calcemic and more potent in calcifying epiphyseal cartilage in rats [41]. The increased potency is likely due to a decreased metabolism of this sterol. In patients with chronic renal failure falecalcitriol was effective in decreasing PTH and appeared to be somewhat more effective than $\alpha$-calcitriol in suppressing SH. [42]. In the United States, 19-nor-1,25$(\mathrm{OH})_{2} \mathrm{D}_{2}$ has been released into the market under the name Zemplar (see above). This vitamin D analog lacks the carbon at position 19. It has been studied extensively and demonstrated to suppress PTH secretion in vitro as potently as calcitriol. Studies in experimental animals have shown that 19 -nor-1,25- $(\mathrm{OH})_{2} \mathrm{D}_{2}$ is effective in suppressing PTH levels with less hypercalcemia and hyperphosphatemia that occur with calcitriol. Indeed 19-nor$1,25-(\mathrm{OH})_{2} \mathrm{D}_{2}$ is approximately ten times less active than calcitriol in mobilizing calcium and phosphate from bone [43]. This vitamin D analog is in widespread clinical use in patients on hemodialysis in the United States and has 
been demonstrated to be effective in suppressing PTH levels. Thus, while three times more 19-nor-1,25-(OH $)_{2} \mathrm{D}_{2}$ than calcitriol is required to achieve equivalent suppression of PTH in animals, studies in patients indicate that a ratio of 3 to 4 is required [44-46]. Similarly, while paricalcitol is ten times less calcemic and phosphatemic than calcitriol in animals, studies in patients with end-stage renal disease on a very low calcium diet have shown that at least eight times more paricalcitol is required to achieve a similar increment in serum calcium presumably representing mobilization of calcium from bone [47]. Sprague et al. [45] demonstrated less severe hyperphosphatemia in patients treated with paricalcitol as compared with those receiving calcitriol. An 18\% decrease in mortality was reported recently in a retrospective study performed over a period of 3 years in patients treated with paricalcitol when compared to calcitriol [48]. The exact mechanism for this effect is not clear at the present time. Another ana$\log$ of vitamin $\mathrm{D}, 1 \alpha$-hydroxy $\mathrm{D}_{2}$, commercially known as Hectorol $^{\circledR}$, is used in the United States for the treatment of SH. This compound is considered a prohormone, since it lacks a 25-hydroxyl group and is metabolized by the liver into an active compound. Comparative studies in normal and uremic animals have shown [49] that $1 \alpha$ hydroxy $\mathrm{D}_{2}$ is more hypercalcemic and hyperphosphatemic than 19-nor-1,25-(OH $)_{2} \mathrm{D}_{2}$. Further studies in patients are necessary to demonstrate this initial observation.

The field of vitamin D analogs is growing very rapidly, and new analogs are being developed in different parts of the world. One of these analogs, calcipotriol, is currently in use for the treatment of psoriasis, and other vitamin D analogs have promising results in animals with experimental malignancies. Thus, in the next decade we will see the appearance of more effective and less toxic vitamin D analogs which will greatly help in the management of $\mathrm{SH}$. Calcimimetic drugs have been developed. These agents greatly increase the sensitivity of the calcium sensor to the actual concentration of serum calcium. Clinical trials have shown significant decreases in the levels of PTH and reductions of the $\mathrm{Ca} \times \mathrm{P}$ product. Although the experience is limited, the use of new calcimimetic drugs will be an important tool in the future for the treatment of $\mathrm{SH}$.

\section{Parathyroidectomy}

Surgical removal of a parathyroid tissue should be considered in patients with severe hyperparathyroidism manifested by a high level of PTH, e.g., intact PTH
$>1,000 \mathrm{pg} / \mathrm{ml}$ with hypercalcemia and/or hyperphosphatemia and elevated $\mathrm{Ca} \times \mathrm{P}$ product that is resistant to or precludes medical therapy. Several surgical procedures have been described, including subtotal parathyroidectomy, total parathyroidectomy with parathyroid tissue transplantation, and total parathyroidectomy. If autotransplantation is undertaken, it is advisable to avoid nodular areas of the gland and to utilize the smallest gland. Total parathyroidectomy is not widely used and is not recommended for patients who may undergo renal transplantation. There is a risk of inducing a low bone turnover state, if total parathyroidectomy is achieved. If total parathyroidectomy is attempted, it is advisable to cryopreserve some parathyroid tissue, so that it may be reimplanted if necessary. Imaging of the parathyroid by 99mTc-sestamibi, MRI, or ultrasonography is not routinely performed by most surgeons and is usually reserved for reoperation. Even after initial successful surgery, the recurrence of hyperparathyroidism may be in the order of $20-30 \%$ after 5 years $[50,51]$. After surgery, some patients may develop hungry bone syndrome, and it is imperative to monitor the levels of calcium carefully, e.g., every $6-12 \mathrm{~h}$ for a few days, and calcium infusion should be given to maintain the levels of total calcium between 7 and $8 \mathrm{mg} / \mathrm{dl}$. Patients may require high doses of calcitriol (up to 3-4 $\mu \mathrm{g} / \mathrm{day}$ ) and calcium carbonate (5-10 g daily).

\section{Management of Calciphylaxis}

The management of calciphylaxis remains a very difficult problem. Attempts should be made to lower the $\mathrm{Ca} \times$ $\mathrm{P}$ product. The serum phosphorus concentration may be lower by using non-calcium-containing phosphate binders (e.g., sevelamer) and intensifying hemodialysis as to increase removal of phosphorus. Calcium supplements and vitamin D should be avoided, as they are known risk factors for the development of calciphylaxis [52-54]. In addition, the use of dialysates containing low calcium concentrations has also been recommended [55]. Parathyroidectomy should be considered only in cases where the PTH levels are elevated. Aggressive control of infections with local care and antibiotic therapy is central in the management of calciphylaxis. Others measures that have been described in the management of this disorder include hyperbaric oxygen chambers and bisphosphonates. 


\section{Integrated Management of Renal Osteodystrophy}

It would seem that an increase in parathyroid activity begins early when the glomerular filtration rate is slightly decreased. When the PTH levels are elevated, it is reasonable to evaluate the vitamin D status by measurement of 25-hydroxyvitamin D levels, and if the blood levels are $<30 \mathrm{ng} / \mathrm{ml}$, vitamin $\mathrm{D}_{2}$ supplementation should be provided to roughly $20,000 \mathrm{U} /$ day or $50,000 \mathrm{U}$ once per month. After the levels of 25-hydroxyvitamin D are adequate, dietary phosphate restriction should be instituted, and the resultant effect of this on PTH levels should be monitored. Phosphate binders should be prescribed with meals. Initially, calcium salts, e.g., $1.5 \mathrm{~g}$ of elemental calcium per day, can be used, since the calcium load can be handled by the kidneys, but if large doses are required, consideration should be given to non-calcium-containing phosphate binders. Currently sevelamer is an excellent phosphate binder. If acidosis is present, it should be treated with sodium bicarbonate. In end-stage renal disease patients, the intact serum PTH concentration should be maintained between 150 and $300 \mathrm{pg} / \mathrm{ml}$. Values $<150 \mathrm{pg} / \mathrm{ml}$ may predispose to the development of adynamic bone disease. On the other hand, values $>300 \mathrm{pg} /$ $\mathrm{ml}$ may predispose the bone to the devolvement of osteitis fibrosa. If calcitriol is given to the patient, intermittent intravenous administration of calcitriol at a dose of 1$4 \mu \mathrm{g} /$ dialysis session should be instituted. The higher the levels of PTH, the greater the amount of calcitriol that should be given to the patients. If an analog like paricalcitol is utilized, the initial dose should be calculated by dividing the PTH level by 100 , e.g., if the PTH concentration is $1,000 \mathrm{pg} / \mathrm{ml}$, the initial dose should be $10 \mu \mathrm{g} /$ dialysis session and adjusted up or down, until the PTH level ranges between 150 and $300 \mathrm{pg} / \mathrm{ml}$. If this is achieved, the dose should be substantially reduced, since further suppression will not only induce adynamic bone disease but also severe hypercalcemia in these patients. All patients should be monitored for aluminum, and the amount of aluminum binders, if prescribed, should be reduced to a minimum and for a short period of time. Calcium citrate should be avoided, since citrate greatly increases the absorption of aluminum. If aluminum is found in bone, chelation should be induced by administration of desferrioxamine. To prevent side effects, the doses should be greatly reduced to approximately $500 \mathrm{mg}$ once a week. After 4-6 months of treatment, serum aluminum should be measured before and after the administration of desferrioxamine $(5 \mathrm{mg} / \mathrm{kg})$ [56]. The combination of an increment in serum aluminum of $>50 \mu \mathrm{g} / \mathrm{l}$ and an intact PTH levels $<150 \mathrm{pg} / \mathrm{ml}$ showed the greatest risk of aluminum bone disease [56].

\section{References}

1 Follis RHJ, Jackson DA: Renal osteomalacia and osteitis fibrosa in adults. Johns Hopkins Med J 1943;72:232.

2 Pappenheimer AM: Effect of an experimental reduction of kidney substance upon parathyroid glands and skeletal tissue. J Exp Med 1936;64:965.

3 Reiss E, Canterbury JM, Kanter A: Circulating parathyroid hormone concentration in chronic renal insufficiency. Arch Intern Med 1969;124: 417-422.

4 Arnaud CD: Hyperparathyroidism and renal failure. Kidney Int 1973;4:89-95.

5 Slatopolsky E, Caglar S, Pennell JP, Taggart DD, Canterbury JM, Reiss E, Bricker NS: On the pathogenesis of hyperparathyroidism in chronic experimental renal insufficiency in the dog. J Clin Invest 1971;50:492-499.

6 Slatopolsky E, Caglar S, Gradowska L, Canterbury J, Reiss E, Bricker NS: On the prevention of secondary hyperparathyroidism in experimental chronic renal disease using 'proportional reduction' of dietary phosphorus intake. Kidney Int 1972;2:147-151.
7 Slatopolsky E, Delmez JA: Pathogenesis of secondary hyperparathyroidism. Am J Kidney Dis 1994;23:229-236.

8 Slatopolsky E, Finch J, Denda M, Ritter C, Zhong M, Dusso A, McDonald PN, Brown AJ: Phosphorus restriction prevents parathyroid gland growth. High phosphorus directly stimulates PTH secretion in vitro. J Clin Invest 1996;97:2534-2540

9 Rutherford WE, Bordier P, Marie P, Hruska K, Harter H, Slatopolsky E: Phosphate control and 25-hydroxycholecalciferol administration in preventing experimental renal osteodystrophy in the dog. J Clin Invest 1977;60:332341.

10 Llach F, Massry SG: On the mechanism of secondary hyperparathyroidism in moderate renal insufficiency. J Clin Endocrinol Metab 1985; 61:601-606.

11 Almaden Y, Canalejo A, Hernandez A, Ballesteros E, Garcia-Navarro S, Torres A, et al: Direct effect of phosphorus on PTH secretion from whole rat parathyroid glands in vitro. $\mathrm{J}$ Bone Miner Res 1966;11:970-976.
12 Kilav R, Silver J, Navey-Many T: Parathyroid hormone gene expression in hyperphosphatemic rats. J Clin Invest 1995;96:327-333.

13 Moallem E, Kilav R, Silver J, Navey-Many T: RNA-protein binding and posttranscriptional regulation of parathyroid hormone gene expression by calcium and phosphate. J Biol Chem 1998;273:5253-5259.

14 Denda M, Finch J, Slatopolsky E: Phosphorus accelerates the development of parathyroid hyperplasia and secondary hyperparathyroidism in rats with renal failure. Am J Kidney Dis 1996;28:596-602.

15 Dusso AS, Pavlopoulos T, Naumovich L, Lu Y, Finch J, Brown AJ, et al: p21 (WAF1) and transforming growth factor-alpha mediate dietary phosphate regulation of parathyroid cell growth. Kidney Int 2001;59:855-865.

16 Tessitore N, Venturi A, Adami S, Roncari C, Rugiu C, Corgnati A, et al: Relationship between serum vitamin D metabolites and dietary intake of phosphate in patients with early renal failure. Miner Electrolyte Metab 1987;13: 38-44. 
17 Nykjaer A, Dragun D, Walther D, Vorum H, Jacobsen C, Herz J, et al: An endocytic pathway essential for renal uptake and activation of the steroid 25-(OH) vitamin $\mathrm{D}_{3}$. Cell 1999;96: 507-515.

18 Brown AJ, Dusso A, Lopez-Hilker S, LewisFinch J, Grooms P, Slatopolsky E: 1,25$(\mathrm{OH})_{2} \mathrm{D}$ receptors are decreased in parathyroid glands from chronically uremic dogs. Kidney Int 1989;35:19-23.

19 Fukuda N, Tanaka H, Tominaga Y, Fukagawa M, Kurokawa K, Seino Y: Decreased 1,25dihydroxyvitamin $\mathrm{D}_{3}$ receptor density is associated with a more severe form of parathyroid hyperplasia in chronic uremic patients. J Clin Invest 1993;92:1436-1443.

20 Patel SR, Ke HQ, Vanholder R, Koenig RJ, $\mathrm{Hsu} \mathrm{CH}$ : Inhibition of calcitriol receptor binding to vitamin $\mathrm{D}$ response elements by uremic toxins. J Clin Invest 1995;96:50-59.

21 Bellorin-Font E, Martin KJ, Freitag JJ, Anderson C, Sicard G, Slatopolsky E, et al: Altered adenylate cyclase kinetics in hyperfunctioning human parathyroid glands. J Clin Endocrinol Metab 1981;52:499-507.

22 Brown EM, Brennan MF, Hurwitz S, Windeck R, Marx SJ, Spiegel AM, et al: Dispersed cells prepared from human parathyroid glands: Distinct calcium sensitivity of adenomas vs. primary hyperplasia. J Clin Endocrinol Metab 1978;46:267-275

23 Felsenfeld AJ, Jara A, Pahl M, Bover J, Rodriguez M: Differences in the dynamics of parathyroid hormone secretion in hemodialysis patients with marked secondary hyperparathyroidism. J Am Soc Nephrol 1995;6:13711378.

24 Russell J, Lettieri D, Sherwood LM: Suppression by $1,25(\mathrm{OH})_{2} \mathrm{D}_{3}$ of transcription of the pre-proparathyroid hormone gene. Endocrinology 1986;119:2864-2866.

25 Silver J, Naveh-Many T, Mayer H, Schmelzer HJ, Popovtzer MM: Regulation by vitamin D metabolites of parathyroid hormone gene transcription in vivo in the rat. J Clin Invest 1986 78:1296-1301.

26 Cozzolino M, Lu Y, Finch J, Slatopolsky E, Dusso AS: P21WAF1 and TGF-alpha mediate parathyroid growth arrest by vitamin $\mathrm{D}$ and high calcium. Kidney Int 2001;60:2109-2117.

27 Arnold A, Brown MF, Urena P, Gaz RD, Sarfati E, Drüeke TB: Monoclonality of parathyroid tumors in chronic renal failure and in primary parathyroid hyperplasia. J Clin Invest 1995;95: 2047-2053.

28 Mucsi I, Hercz G, Uldall R, Ouwendyk M, Francoeur R, Pierratos A: Control of serum phosphate without any phosphate binders in patients treated with nocturnal hemodialysis Kidney Int 1998;53:1399-1404.

29 Braun J, Oldendorf M, Moshage W, Heidler R, Zeitler E, Luft FC: Electron beam computed tomography in the evolution of cardiac calcification in chronic dialysis patients. Am J Kidney Dis 1996;27:394-401.
30 Moe SM, O’Neill KD, Duan D, Ahmed S, Chen NX, Leapman SB, et al: Medial artery calcification in ESRD patients is associated with deposition of bone matrix proteins. Kidney Int 2002;61:638-647.

31 Guerin AP, London GM, Marchais SJ, Metivier F: Arterial stiffening and vascular calcifications in end-stage renal disease. Nephrol Dial Transplant 2000;15:1014-1021.

32 Block GA, Hulbert-Shearon TE, Levin NW, Port FK: Association of serum phosphorus and calcium $\times$ phosphate product with mortality risk in chronic hemodialysis patients: A national study. Am J Kidney Dis 1998;31:607-617.

33 Chertow GM, Burke SK, Lazarus JM, Stenzel KH, Wombolt D, Goldberg D, et al: Poly[allylamine hydrochloride] (RenalGel): A noncalcemic phosphate binder for the treatment of hyperphosphatemia in chronic renal failure. Am J Kidney Dis 1997;29:66-71.

34 Chertow GM, Burke SK, Dillon MA, Slatopolsky E: Long-term effects of sevelamer hydrochloride on the calcium $\times$ phosphate product and lipid profile of haemodialysis patients. Nephrol Dial Transplant 1999;14:2907-2914.

35 Chertow GM, Burke SK, Raggi P: Sevelamer attenuates the progression of coronary and aortic calcification in hemodialysis patients. Kidney Int 2002;62:245-252

36 Jono S, McKee MD, Murry CE, Shioi A, Nishizawa Y, Mori K, et al: Phosphate regulation of vascular smooth muscle cell calcification. Circ Res 2000;87:E10-E17.

37 Hutchison AJ: Calcitriol, lanthanum carbonate, and other new phosphate binders in the management of renal osteodystrophy. Perit Dial Int 1999;19(suppl 2):408-412.

38 Martin KJ, Ballal HS, Domoto DT, Blalock S, Weindel M: Pulse oral calcitriol for the treatment of hyperparathyroidism in patients on continuous ambulatory peritoneal dialysis: Preliminary observations. Am J Kidney Dis 1992;19:540-545.

39 Tsukamato Y, Nomura M, Takahashi Y, Takagi Y, Yoshida A, Nagaoka T, et al: The 'oral 1,25-dihydroxyvitamin $\mathrm{D}_{3}$ pulse therapy' in hemodialysis patient with severe secondary hyperparathyroidism. Nephron 1991;57:23-28.

40 Dusso AS, Negrea L, Gunawardhana S, LopezHilker S, Finch J, Mori T, et al: On the mechanisms for the selective action of vitamin $\mathrm{D}$ analogs. Endocrinology 1991;128:1687-1692.

41 Tanaka Y, DeLuca HF, Kobayashi Y, Ikekawa $\mathrm{N}: \quad 26,26,26,27,27,27$-Hexafluoro-1,25-dihydroxyvitamin $\mathrm{D}_{3}$ : A highly potent, long-lasting analog of 1,25-dihydroxyvitamin $\mathrm{D}_{3}$. Arch Biochem Biophys 1984;229:348-354.

42 Akiba T, Marumo F, Owada A, Kurihara S, Inoue $\mathrm{A}, \mathrm{Chida} \mathrm{Y}$, et al: Controlled trial of falecalcitriol versus alfacalcidol in suppression of parathyroid hormone in hemodialysis patients with secondary hyperparathyroidism. Am J Kidney Dis 1998:32:238-246.

43 Finch JL, Brown AJ, Slatopolsky E: Differential effects of 1,25-dihydroxy-vitamin $\mathrm{D}_{3}$ and 19-nor-1,25-dihydroxy-vitamin $\mathrm{D}_{2}$ on calcium and phosphorus resorption in bone. J Am Soc Nephrol 1999;10:980-985.
44 Llach F, Yudd M: Paricalcitol in dialysis patients with calcitriol-resistant secondary hyperparathyroidism. Am J Kidney Dis 2001;38 (Suppl 5):45-50.

45 Sprague SM, Lerma E, McCormmick D, Abraham M, Batlle D: Suppression of parathyroid hormone secretion in hemodialysis patients: Comparison of paricalcitol with calcitriol. Am J Kidney Dis 2001;38(5 Suppl 5):51-56.

46 Martin KJ, Gonzalez EA, Gellens ME, Hamm LL, Abboud H, Lindberg J: Therapy of secondary hyperparathyroidism with 19-nor-1alpha,25-dihydroxyvitamin $\mathrm{D}_{2}$. Am J Kidney Dis 1998;32(2 Suppl 2):61-66.

47 Coyne DW, Grieff M, Ahya S, Giles K, Norwood K, Slatopolsky E: Differential effects of acute administration of 19-nor-1,25-dihydroxy-vitamin $\mathrm{D}_{2}$ and 1,25-dihydroxy-vitamin $\mathrm{D}_{3}$ on serum calcium and phosphorus in hemodialysis patients. Am J Kidney Dis 2002;40; 1283-1288.

48 Teng M, Wolf M, Ofsthun N, Lazarus M, Lowrie R, Thadhani R: Survival benefit of Zemplar compared to Calcijex among dialysis patients. J Am Soc Nephrol 2002;13:461A.

49 Slatopolsky E, Cozzolino M, Finch JL: Differential effects of 19-nor-1,25-(OH) ${ }_{2} \mathrm{D}_{2}$ and 1alpha-hydroxyvitamin $\mathrm{D}_{2}$ on calcium and phosphorus in normal and uremic rats. Kidney Int 2002;62:1277-1284.

50 Tominaga Y, Tanaka Y, Sato K, Numano M, Uchida K, Falkmer U, et al: Recurrent renal hyperparathyroidism and DNA analysis of autografting parathyroid tissue. World J Surg 1992;16:595-602; discussion 602-603.

51 Gagne ER, Urena P, Leite-Silva S, Zingraff J, Chevalier A, Sarfati E, et al: Short- and longterm efficacy of total parathyroidectomy with immediate autografting compared with subtotal parathyroidectomy in hemodialysis patients. J Am Soc Nephrol 1992:3:1008-1017.

52 Zacharias JM, Fontaine B, Fine A: Calcium use increases risk of calciphylaxis: A case-control study. Perit Dial Int 1999;19:248-252.

53 Campistol JM, Almirall J, Martin E, Torras A, Revert L: Calcium-carbonate-induced calciphylaxis. Nephron 1989;51:549-550.

54 Fine A, Zacharias JM: Calciphylaxis is usually non-ulcerating: Risk factors, outcome and therapy. Kidney Int. 2002;61:2210-2217.

55 Lipsker D, Chosidow O, Martinez F, Challier E, Frances C: Low-calcium dialysis in calciphylaxis. Arch Dermatol 1997;133:798-799.

56 D'Haese PC, Couttenye MM, Goodman WG, Lemoniatou E, Digenis P, Sotornik I, et al: Use of the low dose desferrioxamine test to diagnose and differentiate between patients with aluminum-related bone disease, increased risk for aluminum toxicity, or aluminum overload Nephrol Dial Transplant 1995;10:1874-1884.

57 Martin K, Gonzalez E, Slatopolsky E: Renal osteodystrophy; in Brenner B (ed): The Kidney, ed 7. Philadelphia, Saunders, 2003 (in press). 